\title{
Development of TEM techniques dedicated for characterization of energy related composites and its application
}

\author{
Toshie Yaguchi ${ }^{1}$, Keiji Tamura ${ }^{1}$, Takashi Kubo ${ }^{1}$, Masaki Kondo ${ }^{1}$, Hiroaki Matsumoto ${ }^{2}$, Takahiro \\ Shimizu $^{3}$ and Takeo Kamino ${ }^{3}$ \\ 1. Electron Microscope Systems Design 2nd Dept., Hitachi High-Technologies Corp., Ibaraki, Japan \\ 2. Application Development Dept., Hitachi High-Technologies Corp., Ibaraki, Japan \\ 3. Japan Automobile Research Institute, Ibaraki, Japan
}

In the field of energy-related composites, TEM techniques allowing characterizations of initial structures of electron beam sensitive nano-composites and their dynamics during degradation or synthesis are strongly required [1].

In this paper, recent progress in the improvement of TEM techniques based on a 40-120 kV high resolution analytical TEM and some application to the catalysts are discussed. The spherical aberration coefficient and TEM image resolution of high resolution objective lens at the accelerating voltage of 120 $\mathrm{kV}$ are $1.1 \mathrm{~mm}$ and $0.2 \mathrm{~nm}$ respectively. The high resolution objective lens pole-piece has been newly designed to accommodate a high solid angle silicon drift detector of an energy dispersive X-ray analyzer. A FIB fabricated apertures with the smallest diameter of $1 \mu \mathrm{m}$ are equipped as the field limiting aperture for structural analysis of individual nanometer sized crystalline. The external view of the microscope (HT7700) is shown in Figure 1.

A high-speed turbo molecular pump with the pumping speed of 250 1/s, oil free scroll pump and safety equipment such as gun-air lock valve linking of the gun vacuum enabled high temperature-high resolution in situ TEM observation of solid-gas reactions routinely and safely. Depending on the required gas pressure level at the specimen area, the electron source can be chosen either a $\mathrm{LaB}_{6}$ single crystal emitter or a tungsten hair-pin filament. A gas pressure in the specimen area can be raised up to $0.1 \mathrm{~Pa}$ when the tungsten hair filament is employed.

A compact gas supply system containing three 4.5 litter standard gas cans, giving responsive controlling of specimen atmosphere, has been developed for in situ TEM experiment of gas-solid reaction [2-3]. The flow rates of three gases can be individually and precisely controlled before introduction to the specimen chamber. Figure 2 shows external view of the gas supply system installed on the operation board of a TEM. The length of gas path between the gas supply system and a specimen heating holder equipped with a gas injection nozzle is $20 \mathrm{~cm}$ at minimum. Combination of the short gas path and the local gas injection method to the specimen made time of gas replacement much shorter than that of conventional environmental TEM.

An in situ sequence, taken from a video recording, of the degradation of a Pt/CB electrocatalyst of a fuel cell is shown in Figure 3. Accelerating voltage and electron beam density were $120 \mathrm{kV}$ and $28 \mathrm{~mA} / \mathrm{cm}^{2}$, respectively. The specimen was heated to approx. $200{ }^{\circ} \mathrm{C}$ in the air atmosphere of $0.1 \mathrm{~Pa}$. Structural changes of both carbon support and Pt nano particles are clearly demonstrated.

References:

[1] Kamino T, et al, J. Electron Microsc.54, (2005) pp.497-503. 
[2] Yaguchi T, et al, J. Electron Microsc. 60, (2011) pp.217-225.

[3] Yaguchi T, et al, Proc.of IMC 18, Prague, Czech Republic (2014) ID-12-P-1550.

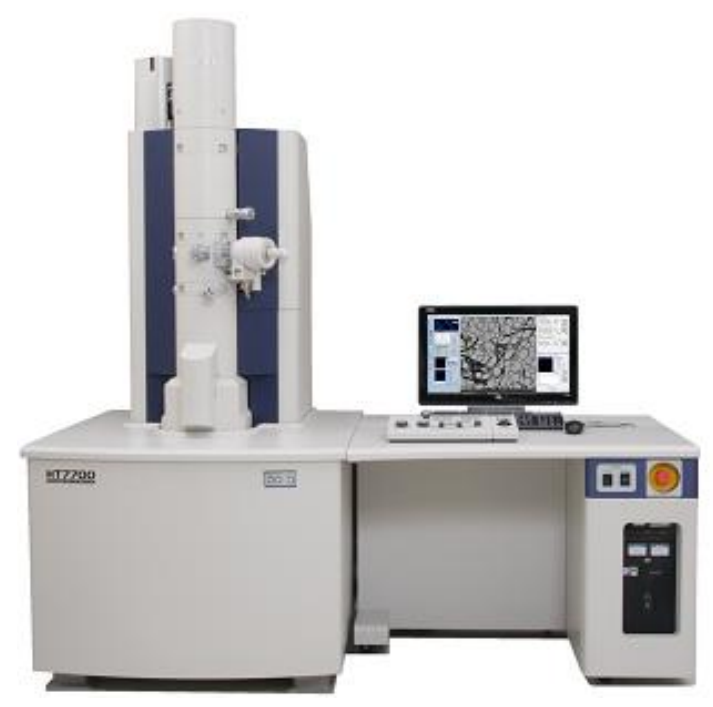

Figure 1. External view of $40-120 \mathrm{kV}$ high resolution analytical TEM.

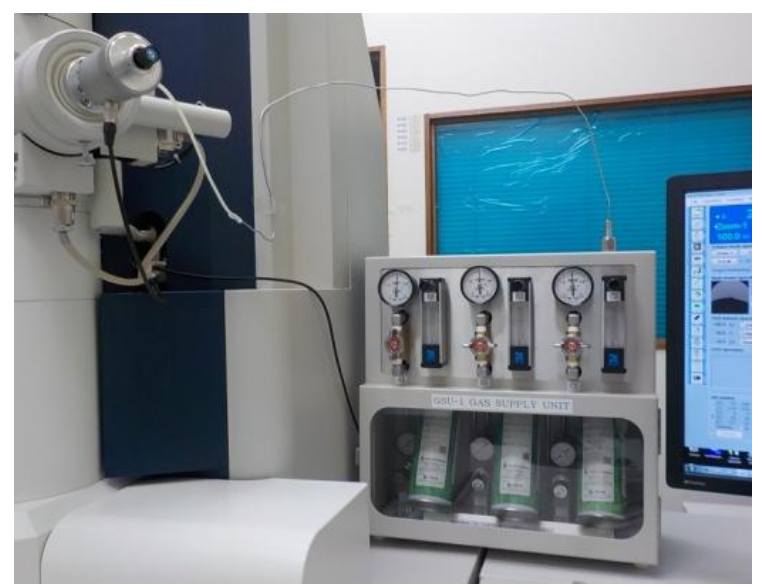

Figure 2. External view of the gas supply system installed on the operation board of a TEM.
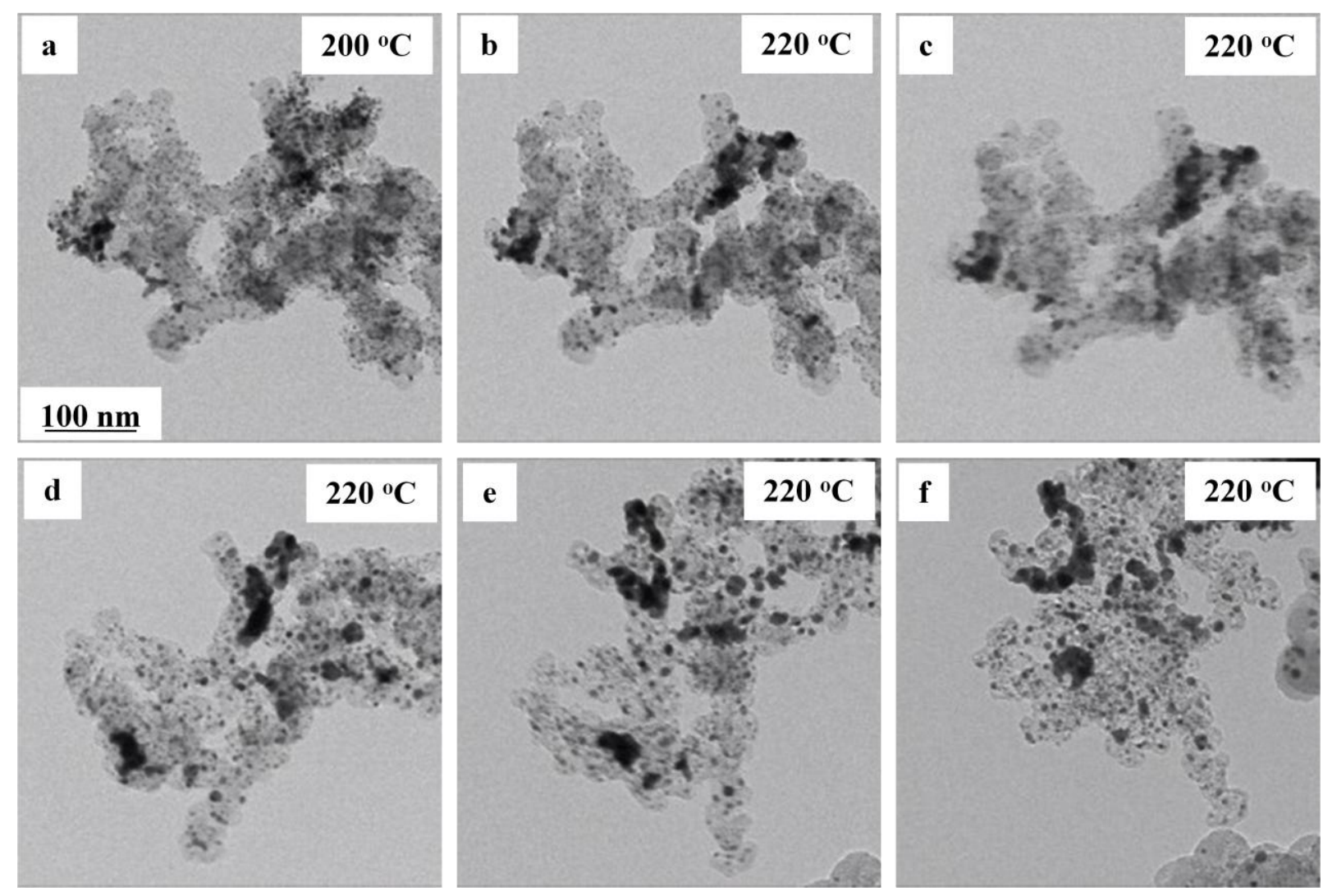

Figure 3. In situ sequence, taken at $120 \mathrm{kV}$, of the degradation of a Pt/CB electrocatalyst of a fuel cell. The specimen was heated to approx. $200{ }^{\circ} \mathrm{C}$ in the air atmosphere of $0.1 \mathrm{~Pa}$. 